\title{
Crystalline to amorphous transformation during irradiation
}

\author{
K G M NAIR* and K KRISHAN' \\ Materials Science Division, Indira Gandhi Centre for Atomic Research, Kalpakkam 603 102, \\ India \\ †National Research and Technology Consortium, Parwanoo 173220, India

\begin{abstract}
Amorphization is often observed during irradiation of intermetallic compounds with energetic charged particles or neutrons. This paper discusses various mechanisms of radiation induced amorphization and also presents the results of amorphization in $\mathrm{Al}-\mathrm{Mn}$ alloys.
\end{abstract}

Keywords. Amorphization; irradiation; point defects; phase instabilities.

\section{Introduction}

Irradiation influences the phase stability through increased defect concentration, enhanced diffusion, segregation and ballistic processes. A variety of phase instabilities are observed during irradiation which include precipitation of thermally unstable phases, dissolution of second phase particles, irradiation induced coarsening, orderdisorder transformation and amorphization. Radiation induced amorphization has been observed in a number of ordered intermetallic compounds, such as $\mathrm{Al}_{6} \mathrm{Mn}$ (Nair et al 1993), $\mathrm{Zr}_{3} \mathrm{Al}$ (Howe and Rainville 1979), $\mathrm{Cu}_{4} \mathrm{Ti}_{3}$ (Luzzi 1991) and $\mathrm{NiAl}$ (Jaouen et al 1991). A number of empirical correlations have been established in these studies. The most important amongst them is that compounds with limited compositional range of existence in the equilibrium phase diagram are the ones which are most susceptible to amorphization. Large negative heat of formation, complicated crystal structure and large difference in the atomic radii of the constituents are the few other features seen in those compounds which undergo amorphization during irradiation. In addition, it is found that temperature of irradiation has a strong influence in the amorphization process. The irradiation induced amorphization is inherently a low temperature phenomenon, since at higher temperatures thermally activated recovery processes become dominant. Various salient features of the radiation induced amorphization process are discussed in the paper by giving specific examples from investigations carried out in Al-Mn alloys.

\section{Mechanisms of amorphization}

The amorphization during irradiation has been attributed to two mechanisms. Naguib and Kelly (1977) proposed a model based on the concept of thermal spikes. The core of a displacement cascade produced during irradiation may be regarded as a hot disordered zone which is equivalent to a liquid. Once produced, such a region may crystallize by epitaxial regrowth onto the surrounding crystalline region or may supercool resulting in the formation of fine amorphous domains in the crystalline

\footnotetext{
*Author for correspondence
} 
matrix. The above process involving displacement cascades is found to be the main cause of amorphization during irradiation with heavy ions. In this case the volume fraction of the amorphous phase $V_{\mathrm{a}}$ is related to the irradiation dose $\phi$ by

$$
V_{\mathrm{a}}=1-\exp (-K \phi)
$$

where $K$ is a constant. However, a mechanism based on displacement cascades alone cannot explain the amorphization observed during irradiation, as amorphization is also seen during electron irradiation (Luzzi et al 1986) where no cascades are produced. Further, dose dependence of the amorphous volume fraction during electron and light ion irradiation is not same as given by (1). In the case of non-cascade producing irradiation, no amorphization is observed until a critical dose is reached. Once the critical dose is reached, the entire sample is converted to the amorphous phase with a very small increase in the irradiation dose. This observation has given rise to the critical defect density model, according to which a critical defect density should build up in the crystalline matrix before amorphization occurs. According to this model, the
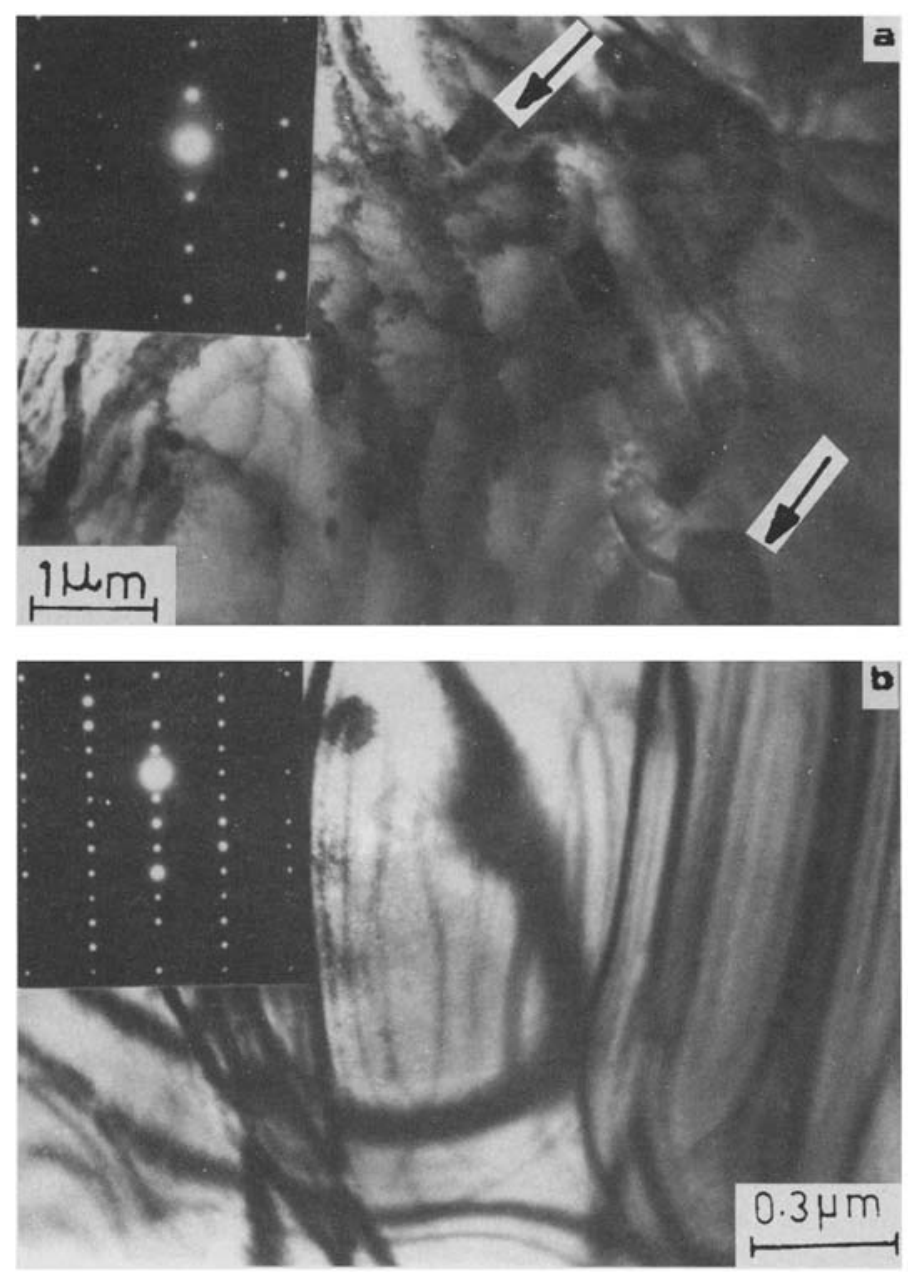

Figure 1. $\mathbf{a}$ and $\mathbf{b}$. 

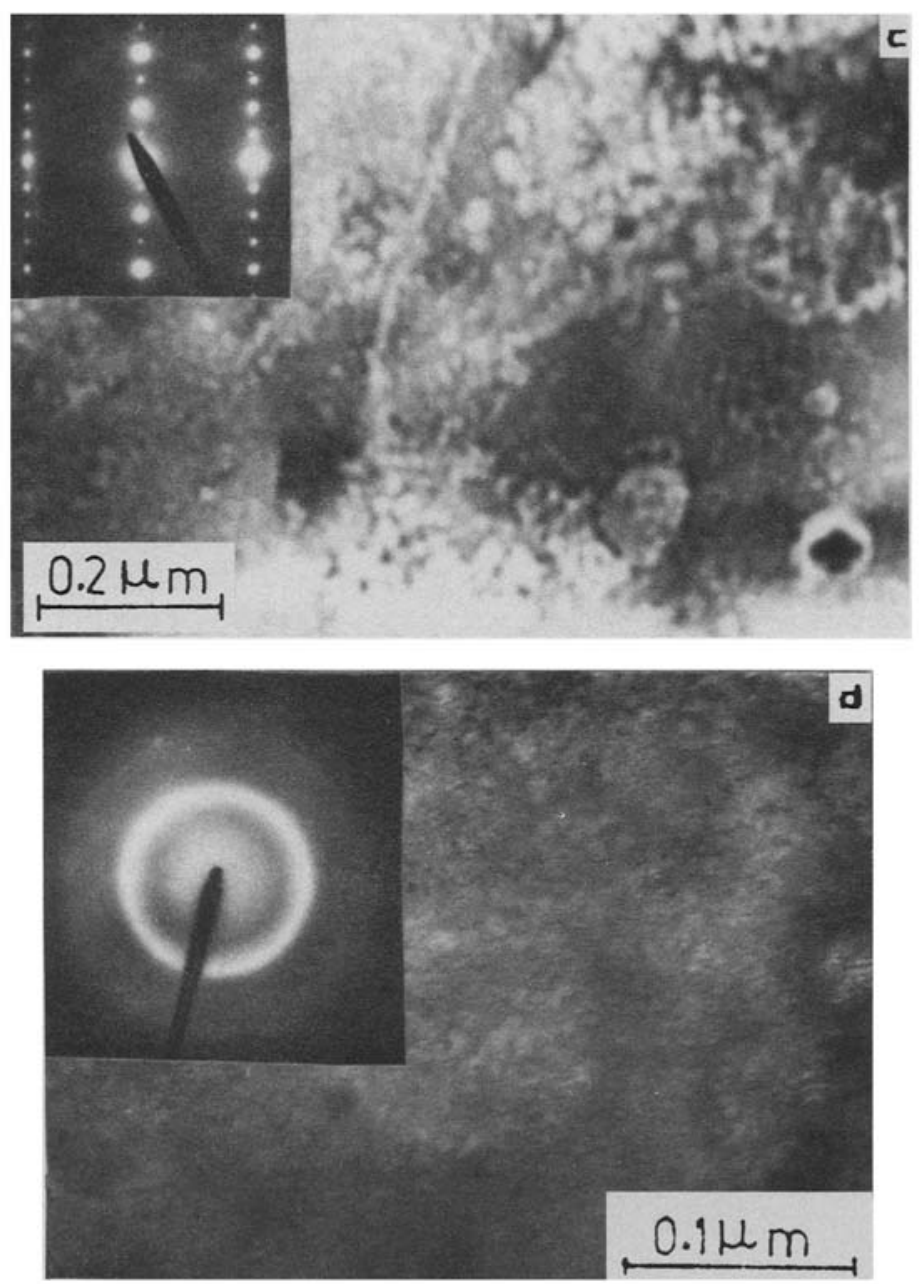

Figure 1. Electron micrographs of the Al-14 a/o Mn alloy irradiated to various doses of $30 \mathrm{keV} \mathrm{He}{ }^{+}$ions. a. Unirradiated alloy showing $\mathrm{Al}_{6} \mathrm{Mn}$ phase (arrow-marked) in $\alpha$-Al matrix, b. dose $=1 \times 10^{16}$ ions $/ \mathrm{cm}^{2}$, c. dose $=2 \times 10^{16}$ ions $/ \mathrm{cm}^{2}$ and d. dose $=4 \times 10^{16} \mathrm{ions} / \mathrm{cm}^{2}$. The insets in each show the corresponding selected area diffraction patterns.

free energy of the crystalline phase increases during irradiation due to the build up of point defect concentration. If the defect density increases to such an extent that the free energy of the crystalline matrix becomes higher than that of the amorphous phase, the crystalline to amorphous transformation occurs. The critical defect density $C_{\mathrm{D}}$ required for the amorphization can be estimated from the difference in the free energy $\Delta F$ between the crystalline and amorphous phases, using

$$
C_{\mathrm{D}} E_{\mathrm{F}}=\Delta F,
$$

where $E_{\mathrm{F}}$ is the formation energy of the defects. Typical values of $\Delta F$ are around $4 \mathrm{~kJ} / \mathrm{mol}$ and $E_{\mathrm{F}}=4 \mathrm{eV}$ for interstitials. The value of the interstitial concentration estimated using the above parameter is around $C_{\mathrm{D}} \approx 0.02$. The value of the critical defect density for amorphization is much higher than the normal steady state defect density observed during 
irradiation which does not exceed $10^{-3}$. The high defect density required for causing crystalline to amorphous transition can build up only on such systems where the defect mobility is very low. Otherwise, processes like recombination, migration to sinks and clustering will reduce the point defect density. In fact, it has been estimated that the migration energy of interstitials should be around $0.8 \mathrm{eV}$ to $1 \mathrm{eV}$ in order to obtain the high point defect densities required for causing amorphization.

\section{Experimental results in Al-Mn system}

In this section, the experimental results on irradiation induced amorphization in Al-Mn alloys are presented and discussed. Two alloy compositions were studied viz. A1-14 a/o Mn and A1-40 a/o Mn. The A1-14 a/o Mn alloy exists in a two-phase field with orthorhombic $\mathrm{Al}_{6} \mathrm{Mn}$ particles dispersed in fcc $\alpha$ - $\mathrm{Al}$ matrix. $\mathrm{Al}_{6} \mathrm{Mn}$ is an ordered line compound which satisfies most of the empirical criteria for amorphization. On the other hand, $\mathrm{Al}-40 \mathrm{a} / \mathrm{o} \mathrm{Mn}$ alloy exists as a single phase with a stoichiometry of $\mathrm{Al}_{8} \mathrm{Mn}_{5}$ over a wide composition range $(10 \%)$. The irradiations were carried out using low energy $\mathrm{He}$ and Ar ions from a low energy accelerator. The irradiated samples were investigated by transmission electron microscopy. The $\mathrm{Al}_{6} \mathrm{Mn}$ phase in $\mathrm{Al}-14 \mathrm{a} / \mathrm{o} \mathrm{Mn}$ alloy exhibited amorphization during irradiation with both $\mathrm{Ar}^{+}$and $\mathrm{He}^{+}$ions. Figure 1 shows a series of electron micrographs of the $\mathrm{Al}_{6} \mathrm{Mn}$ phase irradiated with $30 \mathrm{keV} \mathrm{He}{ }^{+}$ions to various doses. The corresponding selected area diffraction patterns are shown as insets. It is seen that the crystallinity is retained up to an irradiation dose of $1 \times 10^{16} \mathrm{ions} / \mathrm{cm}^{2}$. At a higher irradiation dose of $2 \times 10^{16}$ ions $/ \mathrm{cm}^{2}$, the onset of amorphization can be inferred from the faint diffuse ring appearing in the diffraction pattern. The amorphization is complete at an irradiation dose of $4 \times 10^{16}$ ions $/ \mathrm{cm}^{2}$ as revealed by the diffraction pattern containing only the broad diffuse ring characteristic of the amorphous phase. Figure 2 shows the volume fraction of the amorphous phase as a function

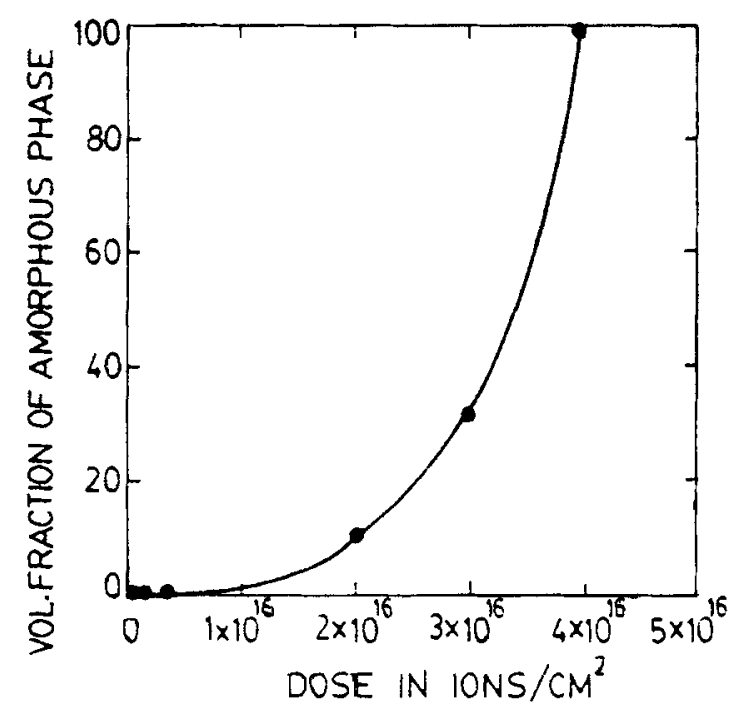

Figure 2. Volume fraction of the amorphous phase as a function of the irradiation dose. 


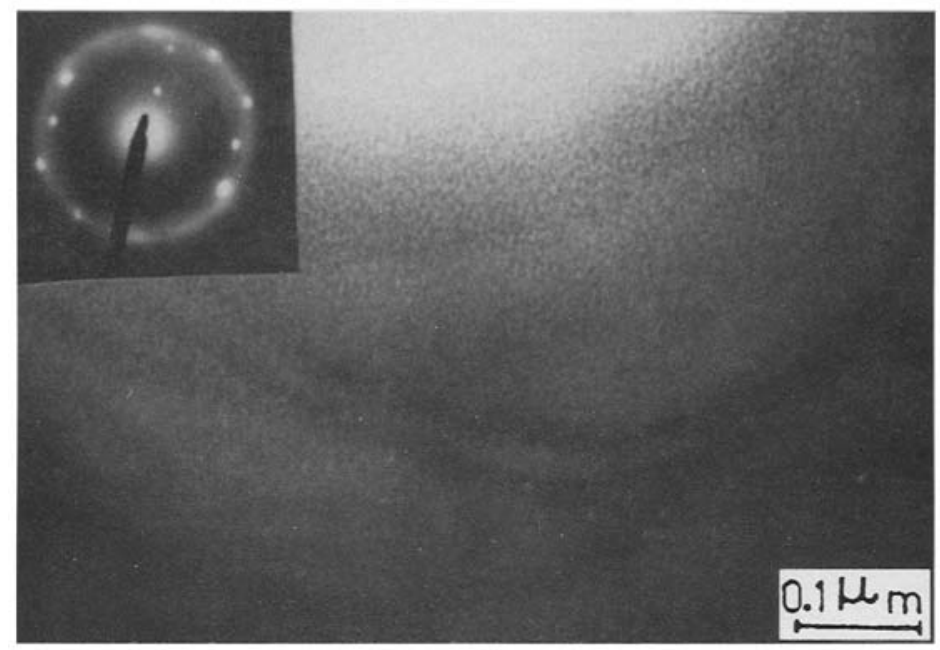

Figure 3. Electron micrograph of $\mathrm{Al}_{6} \mathrm{Mn}$ phase irradiated with $100 \mathrm{keV} \mathrm{Ar}^{+}$ions to a dose of $1 \times 10^{14}$ ions $/ \mathrm{cm}^{2}$. The inset shows the SAD pattern.

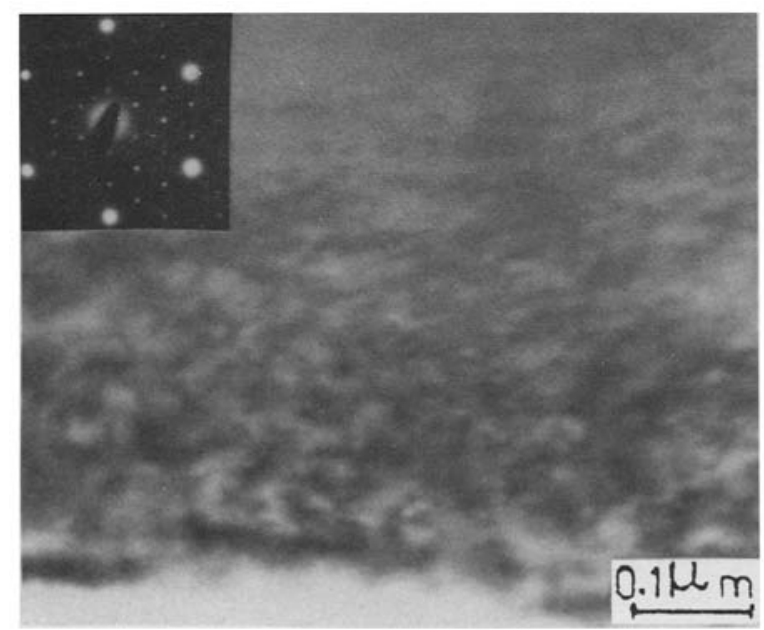

Figure 4. Retention of crystallinity in $\mathrm{Al}_{8} \mathrm{Mn}_{5}$ phase irradiated with $30 \mathrm{keV} \mathrm{He}{ }^{+}$ions to a dose of $2 \times 10^{18}$ ions $/ \mathrm{cm}^{2}$.

of the irradiation dose. It can be seen from the figure that up to a critical dose of $2 \times 10^{16}$ ions $/ \mathrm{cm}^{2}$, there is no amorphization and on reaching the critical dose the amorphous volume fraction increases rapidly with dose. This observation is consistent with the critical defect density model for amorphization discussed earlier, according to which a critical defect concentration has to build up in the sample before the onset of amorphization. Another interesting observation was the absence of defect clusters like dislocation loops in the $\mathrm{Al}_{6} \mathrm{Mn}$ phase during irradiation. This suggests low defect mobility which is an essential pre-requisite for amorphization to occur.

Irradiation of the $\mathrm{Al}_{6} \mathrm{Mn}$ phase with $\mathrm{Ar}^{+}$ions resulted in the formation of the amorphous phase at very low doses. This can be seen from figure 3, where the electron 

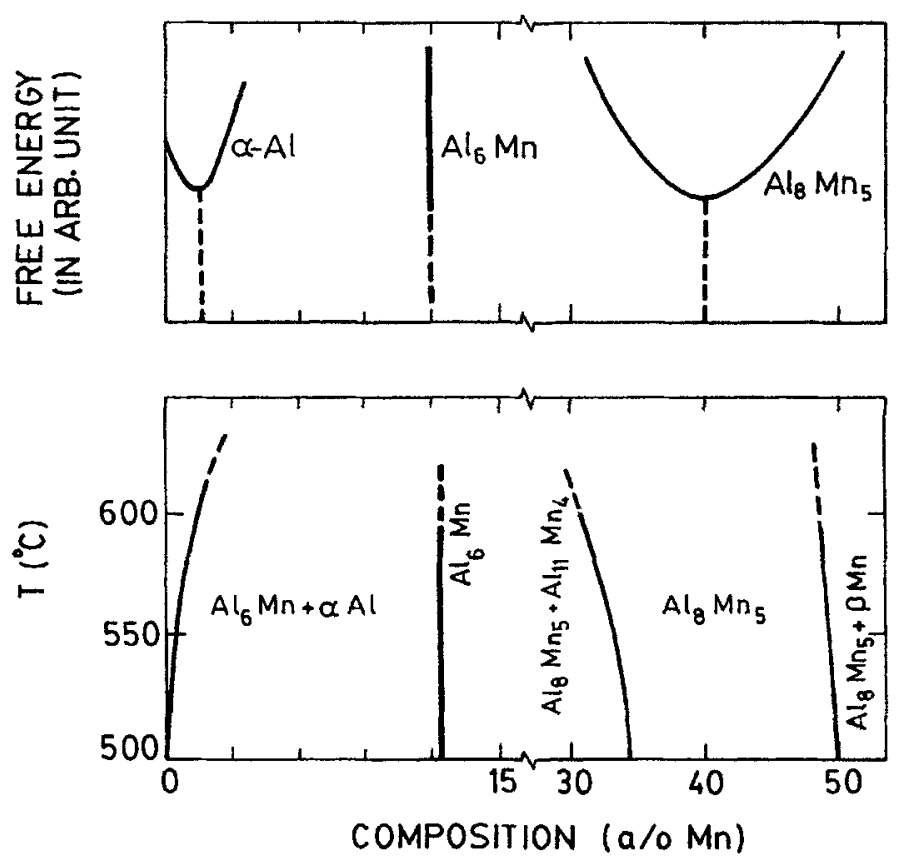

Figure 5. Schematic illustration of the effect of range of homogeneity on the free energy change due to small deviations from stoichiometry, indicated in the relevant portion of the phase diagram.

micrograph of the $\mathrm{Al}_{6} \mathrm{Mn}$ phase irradiated to a dose of $1 \times 10^{14}$ ions $/ \mathrm{cm}^{2}$ with $100 \mathrm{keV}$ $\mathrm{Ar}^{+}$ions and the inset confirm the amorphization of $\mathrm{Al}_{6} \mathrm{Mn}$. In this case, large amount of displacement cascades formed during $\mathrm{Ar}^{+}$ion irradiation is expected to play a dominant role in the amorphization process. When the amorphization is due to displacement cascades, the volume fraction of the amorphous phase is given by (1) and even at very low doses one expects a finite fraction of the amorphous phase.

Investigations on $\mathrm{Al}-40 \mathrm{a} / \mathrm{o} \mathrm{Mn}$ alloy showed that the $\mathrm{Al}_{8} \mathrm{Mn}_{5}$ phase does not become amorphous, despite irradiation to very high doses with both $\mathrm{Ar}^{+}$and $\mathrm{He}^{+}$ ions. Figure 4 shows the electron micrograph and SAD from an $\mathrm{Al}_{8} \mathbf{M n}_{5}$ sample irradiated to a dose of $2 \times 10^{18}$ ions $/ \mathrm{cm}^{2}$ with $30 \mathrm{keV} \mathrm{He}{ }^{+}$ions. It can be clearly seen from the SAD that the crystallinity is retained despite such a high dose of irradiation.

This behaviour of $\mathrm{Al}_{8} \mathrm{Mn}_{5}$ is in sharp contrast with that of $\mathrm{Al}_{6} \mathrm{Mn}$ phase which becomes amorphous at very low doses. It has been well established that the line compounds like $\mathrm{Al}_{6} \mathrm{Mn}$ are susceptible to amorphization during irradiation whereas, the intermetallic compounds which exists over a wide range of composition like $\mathrm{Al}_{8} \mathrm{Mn}_{5}$ are resistant to radiation induced amorphization. Irradiation of an ordered alloy gives rise to local deviations from the stoichiometry due to the production of antisite defects. Such changes will give rise to large increase in free energy of the line compounds as compared to the compounds with wide compositional range of existence in the phase diagram (cf. figure 5).

This effect is illustrated in a hypothetical free energy diagram shown in figure 5 , in which it is seen that very small change in the composition gives rise to large free energy change in the case of $\mathrm{Al}_{6} \mathrm{Mn}$. In contrast to this, in $\mathrm{Al}_{8} \mathrm{Mn}_{5}$ phase, small changes in 
composition does not give rise to significant change in free energy due to the large range of homogeneity of the compound.

\section{Summary}

The crystalline to amorphous transition during irradiation is discussed. The experimental results of investigations in $\mathrm{Al}-\mathrm{Mn}$ alloys using low energy $\mathrm{He}^{+}$and $\mathrm{Ar}^{+}$ion irradiation are presented and discussed in the light of various mechanisms for the irradiation induced amorphization process.

\section{References}

Howe L M and Rainville M H 1979 Philos. Mag. A39 195

Jaouen C, Riviere J P and Delafond J 1991 Instrum. \& Meth. Phys. Res. 59/60 406

Luzzi D E 1991 J. Mater. Res. 62059

Luzzi D E, Mori H, Fujita H and Meshii M 1986 Acta Metall. 34629

Naguib H M and Kelly R 1977 Rad. Effects 3321

Nair K G M, Vijayalakshmi M and Krishan K 1993 Scr. Metall. 29913 